\title{
Continuing Evolution of the Risk Management Function and Education in the United States
}

\author{
by George L. Head *
}

\section{Introduction}

Development of risk management as an integral, indispensable managerial function within any organization has been paralleled in the United States by the growth of educational opportunities for those who aspire to perform this function effectively. This symbiotic evolution can perhaps best be understood by examining first the development of the risk management function, then some of the related educational opportunities, and finally some of the developments which are likely to shape both the risk management function and risk management education in the next twenty years.

\section{Development of the risk management function}

As now understood by general corporate and insurance executives in the United States, risk management is a special subdivision of the discipline of general management - a subdivision having the basic goal of both preventing accidental losses and financing the restoration of those losses which cannot be prevented to enable an organization to fulfill its mission despite actual or potential accidental losses. Understood as a special branch of general management, therefore, it shares the characteristics of all management : risk management is (1) concerned with decision making and with carrying out those decisions with the cooperation of others ; $(2)$ carried out through the universal management functions of planning, organizing, directing, and controlling ; and (3) focused on the achievement of an objective which is fundamental to the organization - here, minimizing the adverse effects of actual and potential accidental losses.

* Director, Risk Management/Loss Control Education, American Institute for Property and Liability Underwriters and Insurance Institute of America. 
Expressed perhaps more succinctly, therefore, industrial and insurance leaders in the United States currently understand risk management to be the planning, organizing, directing, and controlling of the resources and activities of an organization to minimize, through effective loss control and financing, the adverse effects of potential and actual accidental losses upon that organization.

Risk management has not always been so clearly or widely understood, and its acceptance in the United States is by no means universal. In fact, the risk management function was first recognized by students of management not in the United States but in Europe, where Henri Fayol first wrote in 1916 of several essential "organic functions" of management in a book whose title (in the first, 1949 English translation) is General and Industrial Administration. Fayol enumerated these functions as production, sales, finance, organizing and directing, accounting, and security (defined as the protection of property and persons). The first substantial elaboration of this " security function" in the United States - aside from the monthly journal of the Risk and Insurance Management Society, whose predecessors and their publications date from the 1920's - appeared in Robert I. Mehr and Bob A. Hedges' 1963 book, Risk Management in the Business Enterprise. Since then, the United States has seen the publication of numerous collegiate texts and business managers' guides on risk management, reflecting the growing interest in this still emerging discipline.

This burgeoning of literature - and, to some extent, its continuing flavor and orientation - reflect the fact that, in the United States, the risk management function has grown out of insurance buying - as opposed to, say, industrial or safety engineering. This origin has had at least two important implications for risk management as a function in the United States. First, most of the current responsibilities and organizational relationships of a risk manager relate to insurance. For example, most United States risk managers traditionally have reported to the organization's treasurer or the top financial officer. Thus, rooted in insurance buying (which often has been viewed as a clerical activity by senior management), risk management has been seen as a specialized aspect of the financial function. Second, because many organizations have relied upon an outside insurance agent or brokerage to provide their needed property and liability insurance, so these same firms often have looked to an outside agent, broker, or consultant (who usually collects no commissions for selling insurance) as the source of their risk management expertise. As a result, insurance marketing activities in the United States have increasingly gained a risk management flavor as insurance sales personnel, seeking to attract and hold customers, have offered increasingly elaborate " risk management" services, some providing more sophisticated statistical analysis of losses, more complex cash-flow studies, or more elaborate loss prevention than the client itself would be likely to perform internally.

Again, because risk management historically (although not logically nor philosophically) is an outgrowth of insurance, risk management was originally defined, in the eyes of most United States practitioners, in terms of a key insurance concept - pure risk. Therefore, risk management originally focused its loss prevention and loss financing efforts on losses arising from such perils as fire, theft, negligence, or death (where no possibility of gain exists), as opposed to what in the United States are called "speculative" risks. (Speculative risks offer both the chance of gain and of loss from, 
for example, changes in technology, in consumers' tastes, in government regulations, or in market prices.) This initial focus on solely pure risks has led to the mistaken impression among some managers - particularly those not closely allied with the finance function - that " risk management" is simply a glorified term for insurance buying. The pioneers of the risk management function, however, recognized - as do a growing number of executives and academicians throughout the United States that, properly understood and performed, risk management is as essential as any other management function in helping an organization profitably and efficiently reach its goals.

As risk managers first sought general recognition of their specialty as something distinct from both (1) other forms of specialized management (financial, production, marketing, or transportation, for example) and (2) general senior executive leadership, the distinction between pure and speculative risks again provided the key. All profit-seeking organizations, risk managers argued, seek to take on speculative risks in order to generate profits. However, as they also pointed out, these profitseeking activities necessarily exposed an organization to pure risks. It is these pure risks, the pioneers argued, which are the special domain of risk management. Thus, risk management practitioners and analysts initially contended, risk management encompasses all of an organization's activities - not just its production, finance, marketing, or transportation - but only the pure risk aspects of these activities.

This early striving for recognition as management specialists led risk managers to come into contact with managers of other, longer-established functions, who were at least incidentally concerned with the pure risk aspects of their profitseeking activities. Risk managers found that one of the most effective ways of gaining the cooperation of these other managers was to demonstrate how sound risk management could expedite and make more efficient the fulfillment of other managers' objectives - helping these other managers overcome the barriers or extra costs imposed by, for example, finding a safe packaging material in which to market a new food product or developing better means of transporting fragile cargoes.

This cooperative stance in seeking recognition has, in recent years, begun to break down the pure/speculative risk dichotomy which first demarked the special realm of the risk manager. The later, and still emerging, recognition by risk managers and other executives that pure and speculative risks are inextricably intertwined has, at least in the better-managed organizations within the United States, led to the inclusion of a risk manager in the general management team which combines their diverse talents in making key policy decisions. More and more frequently, for example, risk managers are being asked to participate in, or give advice on, such decisions as where to locate a factory, whether and or how to produce a product, which types of machinery to purchase, and whether or on what terms to merge with another organization (whose loss exposures may affect the profitability or the efficiency of the merged organizations).

In those relatively few enlightened organizations in which risk management has been fully accepted because of its contributions to profits or efficiency (through reduced costs and/or increased revenues or output, often from projects once thought too risky 
to venture), risk managers have found that they must explain and justify their activities and recommendations on the basis of the same performance criteria which are applied to each of the organization's other activities. The most important of these criteria typically is the impact on the present value of the organization's net cash flows. Risk managers increasingly are learning to evaluate and present their programs in terms of their positive effects on the amounts and timing of the organization's net cash flows : prevention of losses to reduce cash outflows for self-insured losses or for experiencerated insurance coverages; various forms on self-insurance (more accurately termed " risk retention") to reduce outflows for insurance premiums ; premium financing plans to defer payment of insurance premiums ; and "captive" (more accurately, "affiliated subsidiary") insurers operating as positive profit centers.

Increasing integration with general management has also led alert risk managers to borrow from other business and scientific disciplines to strengthen their own performance and to more effectively explain the importance of risk management to others. One of the most valuable concepts risk managers have borrowed comes from the basic physical sciences : the general notion of a decision-making or problem-solving process, where the "problem" is the possibility of accidental losses. As often stated in five (or perhaps a different number of) steps, the basic risk management decision process is coming to be recognized as :

(1) identifying and analyzing loss exposures in terms of (a) what may happen and (b) how likely and how severe the losses may be ;

(2) examining alternative risk management techniques for dealing with each of these exposures through a variety of (a) loss control measures (to reduce the frequency and/or severity of accidental losses) and (b) loss financing techniques to pay for those losses which are not prevented (using either internally-generated funds through " risk retention" or externally-generated funds through "risk transfer");

(3) choosing, for each significant loss exposure, the most cost-effective risk management technique (or, more likely, the best mutually-reinforcing combination of loss control and loss financing techniques);

(4) implementing the chosen techniques through a combination of (a) technical decisions, which are the risk manager's exclusive domain, and (b) managerial decisions, which require the cooperation of the risk manager with other managers and personnel throughout the organization;

(5) monitoring the results of the chosen risk management techniques to assure that they achieve the desired objectives and also that they are adjusted for any charges in loss exposures.

Borrowing from other disciplines, and demonstrating to practitioners of other disciplines how their work is germane to risk management has helped risk managers to explain, in turn, how risk management is relevant to practitioners of other disciplines as well as to managers of other functions. In teaching others the importance of risk management, the perceptive risk manager also is learning others' disciplines, thus becoming somewhat of a "Rennaisance person" on the modern management team. 


\section{Educational opportunities in risk management}

Rapid evolution of the risk management function - from the "insurance recorder" of the 1920's to the "Rennaisance person" of the 1980's - has left in its wake, at least in the United States, a rather wide variety of educational offerings which bear the label "risk management." Of the perhaps 120 United States colleges and universities which offer a course or a major in "risk management," well over half do so through courses entitled "Insurance and Risk Management." In many of these courses, risk management is intended to be a more sophisticated way of buying insurance in conjunction with other ways of dealing with accidental losses. Perhaps only a dozen universities offer a major which attempts to educate the "Rennaisance person" of risk management - to teach an integrated decision process in which insurance is only one (and perhaps the least cost-effective) technique for dealing with accidental losses.

It is encouraging, however, that an increasing number of universities - particularly those which are initiating new risk management and insurance curricula, as opposed to grafting risk management onto existing insurance programs - are taking the more enlightened, decision-making path toward educating effective risk managers. The most current available information on insurance and risk management courses now offered in the United States is available through the S. S. Huebner Foundation for Insurance Education, at the University of Pennsylvania.

Aside from these university offerings, which may lead to a baccalaureate, masters, or doctoral degree in insurance and risk management, a professional designation in risk management ("Associate in Risk Management") is offered by the Insurance Institute of America to all those who complete a three-semester course of study and examination program, available throughout the free world. This program explores in detail the five-step risk management process set forth above and is designed to develop patterns of thought useful in managing loss exposures for any organization. The program does not, however, focus on the particular risk management challenges of any specific industry.

For risk management in a particular industry, or for information on current developments in insurance markets, tax regulations, or loss control, a great number of organizations in the United States offer special seminars, which may run for a few days or a week. Such seminars may be available through trade associations for a particular industry or through such groups as the American Management Association or the Risk and Insurance Management Society. The quality of these seminars as well as their place on the spectrum between the "insurance recorder" and the "Rennaisance person" - depends upon the sponsoring organization, the subject of the seminar, and the individual seminar leaders.

With the great variety of risk management educational opportunities available in the United States, there is some danger that "risk management" may become an empty bit of jargon, a flag waved by those seeking others' participation in their programs. Evaluating specific educational offerings in risk management can be difficult because the discipline labeled "risk management" is still emerging, and honest people 
may differ as to what the key elements of this discipline are. Two generally useful standards are, first, the extent to which an educational offering integrates risk management with other disciplines and, second, the degree to which the offering addresses itself to some crucial challenges which are likely to face risk managers in the coming decades.

\section{Risk management challenges of the coming decades}

As executives in the United States and throughout the world develop greater appreciation of risk management, they are likely to demand more of those who manage risks. Specifically, between now and the year 2,000, it seems reasonable to expect that risk managers will have to pay increasing attention to (1) diverse organizational objectives beyond, and perhaps conflicting with, the traditional goal of profit ; (2) loss control as a humanitarian objective largely unrelated to cost; and (3) changing organizational relationships as the technical and managerial aspects of risk management become unified.

The first of these trends, changing organizational goals, is likely to mean that tomorrow's risk manager will be asked to do more than protect the organization's assets and activities against accidental losses. He or she will increasingly be required to select that combination of risk management techniques which will foster such diverse objectives as promoting growth, stablizing earnings, assuring continuity of operations on at least a minimum (not necessarily full) scale regardless of catastrophes, and keeping accident-related fluctuations in owners' earnings within specified bounds.

Achieving any of these new objectives, let alone combinations of them, will require greater sophistication in selecting risk management techniques than is now generally practiced. It may also require more extensive loss financing as the organization's risk management objectives extend beyond mere survival to more demanding standards of acceptable risk management performance. Furthermore, the growth of risk management for public entities - particularly for municipal and state governments, whose financial resources often are assured by the sovereign power to tax - is likely to call for risk management decision criteria based on goals other than profitability, growth, or earnings stability. Public service through risk management management of the public's risks for the public good - may become a primary goal.

A second concern of the coming decades is likely to stem from senior management's recognition that loss control often is much more cost-effective than loss financing - whether through insurance or other techniques for generating funds. Therefore, tomorrow's risk manager will need to branch out farther beyond his or her insurance roots into the engineering aspects of loss control. $\mathrm{He}$ or she will need to undertake educational, enforcement, or engineering measures to stop losses from happening, thereby averting much human suffering and property loss. Such losses are likely to be viewed as a net drain on society's resources (regardless of how expertly the risk manager has arranged to finance restoration of these losses). Avoiding the human suffering they typically engender will increasingly become a social responsibility of the modern corporate citizen and of the risk manager as an individual professional. 
As loss control and loss financing come to be viewed as the two necessary, inseparable aspects of protecting an organization and society against the adverse effects of accidental losses, there may well come an increasing demand for unifying the loss control and financing functions. Within any given organization, the executive who succeeds to this new, unified managerial post will be the one who best combines knowledge of loss control and of loss financing with the ability to work with others to make both technical decisions as to precisely what should be done (such as which type of fire-suppression system to install) and the managerial decisions as to how to carry out these steps (such as when to install the system and who should be responsible for its maintenance). For yesteryear's insurance clerk to successfully meet this new managerial challenge - to continue to evolve as a true "Rennaisance" risk manager - he or she will need to personally learn more about loss exposures and to teach and inspire others how best to deal with them. As technology and loss exposures continue to evolve, so must risk management - and those who practice it. 